\title{
A Scoping Review of the Effects of COVID-19 Medications on Pregnancy
}

\author{
Ahmed M Abbas ${ }^{1,2 *}$, Islam H Ibrahim ${ }^{2,3}$, Micheal Mikael ${ }^{2,4}$, Safaa K Fathy ${ }^{2,5}$, Lobna Ahmed ${ }^{2,5}$, Dina B Ahmed6, \\ Ahmed M Mahmoud ${ }^{2,3}$, Sarah K Fahmi ${ }^{2,3}$ and Nehal G Omar ${ }^{2,3}$ \\ ${ }^{1}$ Department of Obstetrics \& Gynecology, Faculty of Medicine, Assiut University, Egypt
}

${ }^{2}$ COVID-19 Research of Assiut University Association (CORAUNA) group, Egypt

${ }^{3}$ Undergraduate student, Faculty of Medicine, Assiut University, Egypt

${ }^{4}$ Resident physician, Ahmed Maher Teaching Hospital, Cairo, Egypt

${ }^{5}$ House officer, Faculty of Medicine, Assiut University, Egypt

${ }^{6}$ House officer, Mansoura University Hospitals, Mansoura, Egypt

*Corresponding author: Ahmed M Abbas, Professor, Department of Obstetrics and Gynecology, Assiut University, Women Health Hospital, Egypt.
Received Date: July 28, 2020

Published Date: August 26, 2020

\begin{abstract}
COVID-19 is a pandemic disease caused by the SARS-CoV-2 which began to appear around in December 2019 in Wuhan, China and spread globally in the last few months. Currently, there is no specific treatment for SARS-CoV-2 which forced clinicians to use old drugs, chosen for their efficacy against similar viruses or their in vitro activity. The majority of information comes from small case series and single center reports which showed that COVID-19 infection in pregnant women can lead to intrauterine growth restriction, premature labor and spontaneous abortion. So, in the view of the urgency of COVID-19 pandemic and the uncertainties about its management during pregnancy, we aimed to provide a literature review on the effectiveness and safety of available medications for COVID-19 in pregnant women. Here, our overview may provide useful information for physicians to choose the best available medications for treatment a pregnant case with COVID-19.
\end{abstract}

Keywords: COVID-19; Pregnancy; Medications

\section{Introduction}

In Wuhan, China, coronavirus disease-2019 (COVID-19) began to appear in December 2019 [1]. It is caused by severe acute respiratory syndrome coronavirus-2 (SARS-Cov-2), this is a new type of enveloped RNA viruses characterized by mild infection in upper respiratory tract and life-threatening pneumonia [2]. The number of the affected pregnant women is increasing as pregnancy is a special immunological case in which the immune system is exposed to great challenges involving maintaining and establishing adaptation to allogenic fetus and preserving fetus from any microbial challenges. The immune system in pregnancy undergoes three stages; pro-inflammatory state in the first trimester, antiinflammatory state in the second trimester and second proinflammatory state in the third trimester [3].

During pregnancy the upper respiratory tract is swollen due to high levels of estrogen and progesterone which restrict lung expansion, and this increase the incidence of viral infection. Recent literature explains that COVID-19 infection is associated with cytokine storm in severe cases in which there is increased 
plasma concentration of tumor necrosis factor alpha, macrophage inflammatory protein1 alpha, monocyte chemoattractant protein1, granulocyte-colony stimulating factor, interferon gamma inducible protein10, interleukins (IL-2), (IL-7), (IL-10). Based on the proinflammatory state in third and first trimester in pregnancy and cytokine storm in COVID-19 infection the pregnant women are exposed to severe inflammatory state which can affect the fetal brain and leads to several aspects of neuronal dysfunction $[3,4]$. Also, elevated levels of TNF alpha in mother's peripheral blood can be toxic to early embryo development and induce preterm delivery in non-human models [5].

Previous studies have explained that COVID-19 infection in pregnant women can lead to intrauterine growth restriction, premature labor and spontaneous abortion [6]. Therefore, treatment must be initiated when potential benefits outweigh potential risks and intra uterine development must be monitored closely during treatment and even after the treatment is stopped [7]. Due to the urgency of COVID-19 pandemic and the uncertainties about its management during pregnancy, we aimed to provide a literature review on the effectiveness and safety of available medications for COVID-19 in pregnant women. After we reviewed the guidelines and protocols from National institution of health (NIH), United Kingdom National Health Service (NHS), Egypt, Saudi Arabia, France, Italy, Spain and China, we limited our search on the most relevant medications mentioned in them. We also limited our search on English-language literature.

\section{Chloroquine and Hydroxychloroquine}

Chloroquine and hydroxychloroquine are antimalarial and antirheumatoid drugs. They are weak bases and have deep volume of distribution and half-life around 50 days. These drugs cause defect in the lysosomal activity and autophagy, interfering with stability of cell membrane and causing defect in pathway of signaling and transcriptional activity leading to inhibition of cytokine production and modulating certain co-stimulatory molecules. Both drugs are enantiomers [8]. Chloroquine and hydroxychloroquine are category $\mathrm{C}$ according to FDA [9]. Studies showed that they have a broadspectrum antiviral effect by increasing endosomal $\mathrm{PH}$ required for virus $\backslash$ cell infusion and causing defect in glycosylation of cellular receptors of SARS-COV. They also have anti-inflammatory effect plus their anti-viral effect which are responsible for their potent effect in treating COVID-19 [10]. Chloroquine can cross the placenta and accumulate in the fetal tissues as hydroxychloroquine which tend to accumulate in melanin containing tissues as retina and choroid leading to loss of vision [11].

On follow up of infants that their mothers took hydroxychloroquine during gestation and lactation, Hart and Naughton presenting that the main complication is preterm delivery (20.5\%), no significant neonatal infections or congenital anomalies were observed, including infants that were breastfed. They concluded that hydroxychloroquine seems to be safe during pregnancy and preterm delivery reflects the state of maternal disease [12]. Suhonen reported a case receiving hydroxychloroquine phosphate in the first six weeks of pregnancy to control discoid systemic lupus erythematosus and fetus was born with no anomalies and grew without any mental or physical abnormalities [13]. Ross and Garotos examined autopsy from 14-week aborted fetus as his mother taking chloroquine showing no anomalies in oropharynx [14].

Additionally, eight patients who were presented to American Rheumatism Association, these patients had 28 pregnancies, they were receiving chloroquine, three of them underwent incomplete pregnancy or neonatal death as they came during period of activity of the disease, one had still birth fetus, four underwent spontaneous abortion and six had full term standard deliveries [15]. A meta-analysis conducted on hydroxychloroquine included seven cohort studies and one randomized controlled trial showed no significant increase in the rates of major congenital, craniofacial, genitourinary, cardiovascular, nervous system malformations, stillbirth or prematurity. Unfortunately, there is no data about the effect of chloroquine on pregnant women with COVID-19.

\section{Remdesivir}

Remdesivir is small molecule broad spectrum antiviral drug which act as RdRp inhibitor targeting viral genome process of replication. It is recommended to be safe during pregnancy in COVID-19 infection as in trials conducted of Marburg virus and Ebola virus [16]. In reproductive non-clinical toxicity, there is no adverse effects were noticed on embryo-fetal development in male infertility or pregnant animal with Remdesivir. In photoactivated localization microscopy study of acute Ebola virus disease, $26 \%$ of children and 3\% of pregnant women received Remdesivir without any notable adverse effect [17].

\section{Interferons (IFN- $\alpha$ and IFN- $\beta$ mainly)}

Type I interferons (IFN- $\alpha / \beta)$ have broad spectrum antiviral activities against RNA viruses by inducing an antiviral response across a wide range of cell types and stimulating the host adaptive immune response [18]. Data from several pregnancy registries showed no association between preconception or during pregnancy exposure to interferon-beta- $1 \mathrm{~b}$ and an increased risk of adverse birth outcomes [19]. A meta-analysis conducted to observe whether type I interferon has adverse effects on pregnant women with primary thrombocytopenia. The results showed that IFN- $\alpha$ did not significantly increase the risk of malformations, miscarriages, stillbirths, or premature births [20]. Another large systematic review included 50 studies that identified 761 pregnancies exposed to interferon $\beta$. Results reported that exposure to interferon $\beta$ was associated with shorter mean birth length, lower mean birth 
weight, and preterm birth $(<37$ weeks); however, there was no increased risk of serious pregnancy complications of spontaneous abortion, cesarean delivery or birth weight $<2.5 \mathrm{~kg}[21]$.

A recent study included data from 26 European countries evaluated pregnancy outcomes of 948 pregnant women with multiple sclerosis receiving IFN I- $\beta$ during pregnancy or within one month before conception. Results did not show an increased risk of fetal malformations or spontaneous abortion [22]. Currently, IFN type I is classified as US FDA pregnancy category C.

\section{Janus Kinase Inhibitors (e.g., Baricitinib)}

Baricitinib is a potent and selective janus Kinase Inhibitor that is used for treatment of rheumatoid arthritis and currently being investigated for treatment of COVID-19 cases due to its antiinflammatory and antiviral activities [23] as it would likely prevent the dysregulated production of pro-inflammatory cytokines in COVID-19 cases [24]. There are limited human data on the use of baricitinib to evaluate the drug-associated risk for major birth defects or miscarriage. In animal studies of embryo-fetal development, there was increased embryo lethality in some species that were given baricitinib at very high doses, above the maximum human recommended dose [25]. Baricitinib is not assigned in the US FDA pregnancy categorization. But It is classified as AU TGA (Australian categorization) pregnancy category: D.

\section{Interleukin-1 Inhibitors (e.g., Anakinra)}

Interleukin-1 is a pro inflammatory cytokine binds to IL-1 receptor and modulate its action so inhibitors of interleukin-1 are used to treat rheumatoid arthritis and currently being investigated for treatment of COVID-19 due to its potential effect to interfere with the cytokine storm in severe cases of COVID-19 [26]. There is limited evidence about the use of Interleukin-1 inhibitors(IL-1) in pregnancy but unintentional first trimester exposure is unlikely to be harmful [27]. According to an International multi-center study of the pregnancy outcomes in pregnant women exposed to interleukin-1 inhibitors, the use of interleukin-1 inhibitors may not significantly affect pregnancy outcomes or infant development. The study identified a total of 43 pregnancies with IL-1 inhibitors exposure in 7 countries, including 8 maternal from 14 with canukinumab and 23 maternal from 29 with anakinra. Seven healthy infants of normal gestational age and birthweight delivered from eight pregnancies exposed to canukinumab. Twenty-one healthy infants, and one baby with unilateral renal agenesis and ectopic neurohypophysis delivered from 23 pregnancies exposed to anakinra [28]. Anakinra is classified as US FDA pregnancy category B and AU TGA pregnancy category: B1.

\section{Interleukin-6 Inhibitors (e.g., Tocilizumab)}

Interleukin-6 (IL-6)is a pro-inflammatory cytokine that activates its downstream Janus kinase (JAK) signal by binding the transmembrane (cis-signaling) or soluble form (trans-signaling) of the IL-6 receptor [29]. Tocilizumab is a monoclonal antibody used for the treatment of rheumatoid arthritis and currently being investigated for treatment of some cases of severe COVID-19 with good results [30]. There are insufficient data to determine if there is a drug-associated risk for major birth defects or miscarriage [31]. A study analyzed pregnancy-related reports of 399 women with Tocilizumab exposure shortly before or during pregnancy. Pregnancy outcomes were reported in 288 pregnancies $(72.2 \%)$ and showed no indication for a substantially increased malformation risk but the data do not yet prove safety [32]. Another Japanese retrospective study included 61 pregnancies with rheumatic disease exposed to tocilizumab during conception. Results showed no increased rates of spontaneous abortion or congenital abnormalities [33]. Tocilizumab is classified as US FDA pregnancy category $\mathrm{C}$ and $\mathrm{AU}$ TGA pregnancy category: $\mathrm{C}$.

\section{HIV Protease Inhibitors (e.g., Lopinavir/Ritonavir Darunavir/Cobicistat)}

Lopinavir and Darunavir work as competitive inhibitors through binding directly to HIV protease and prevent subsequent cleavage of polypeptides, which in turn reduce viral replication and spread. Ritonavir and Cobicistat are metabolism-based enhancer to increase the exposure of Lopinavir and Darunavir [34]. Both drugs are used for treatment of HIV-infected women during pregnancy and prevention of mother-to-child transmission. In spite of their efficacy in vitro against SARS-CoV, they have poor selectivity index requiring higher than the tolerable level to achieve the clinically significant inhibition in vivo; however, based on systemic review and clinical studies found when given early to be associated with lower hospital stay and lower mortality rates [35-37].

Lopinavir is one of the main HIV protease inhibitors recommended in pregnancy with a good safety profile. Pharmacokinetics studies reported lower exposure of LPV in pregnancy [38] due to moderate decrease of total Lopinavir concentrations despite the dose increase [39]. However, the exposure of unbound LPV did not change significantly regardless of trimester or dose [40]. Two cohort studies of 21 women conducted with steady pharmacokinetic evaluations concluding that improving the oral bioavailability of the tablets may compensate for the reduction in exposure during the later stages of pregnancy [41]. Therefore, a population pharmacokinetic analysis conducted to assess the statically significance doesn't show clinically meaningful difference between Lopinavir exposure in pregnant women receiving the tablet and non-pregnant receiving the capsule and dose adjustment isn't needed [42]. However increased doses may be preferable in obesity ( $>100 \mathrm{~kg}$ ) and with a previous history of LPV/RTV use and/or compliance issues [43]. Bearing in mind that increasing the dose didn't correlate with frequent adverse effects 
according to a random clinical trial [44] and didn't result in greater neurodevelopmental risks for HIV positive mothers or uninfected infants [45].

Despite the high frequency of maternal adverse effects, they are mostly of low severity hence LPV is considered safe throughout pregnancy. It is not assigned in FDA pregnancy category, however; it's classified by AU TGA pregnancy category as: B3

Darunavir is not recommended to use in pregnancy due to the great diminished exposure in second and third trimesters of pregnancy leading to increase the risk of virologic failure during pregnancy and must be boosted by Ritonavir low dose [46]. A large non blind clinical trials of 28 women supported by pharmacokinetic studies has found that using DRV/COBI during pregnancy is associated with reducing the exposure of total DRV area under the curve by $33 \%$ and $48 \%$ and DRV trough concentrations were reduced by $71 \%$ and $75 \%$ [47]. Prevalence of birth defects for pregnancies of women on Darunavir-containing regimens in the first trimesters $0.4 \%$ higher than the control population according to the Antiretroviral Pregnancy Registry [48]. Preterm delivery and low birth weight have been noted as adverse outcomes, but correlation isn't established [49]. It is not assigned in FDA pregnancy category and classified by AU TGA pregnancy category as: B2

\section{Ivermectin}

Ivermectin is one of the most widely used anti-parasitic drugs for animals and humans. Its main action is to inhibit the importin family of nucleus-cytoplasmic transporters which is responsible for transmitting viral proteins into the host cell nucleus. A metaanalysis covering several animal studies showed its effectiveness against both RNA and DNA viruses but lack human studies [50]. Based on a systemic review of the safety of Ivermectin treatment in pregnant women conducted on five retrospective case control studies and one random clinical trial concluding the absence of evidence for excess abnormal birth outcomes in woman who received Ivermectin during pregnancy. Despite the serious unfavorable outcomes regardless of the dose, no correlation between adverse effects and Ivermectin administration can be assessed because the intended studies weren't designed to focus on the safety of Ivermectin use throughout pregnancy [51,52]. Further reproductive toxicological studies and randomized clinical trials are needed to reach conclusive results. The drug is already in clinical trials all over the world, but pregnant women are excluded as a vulnerable group making the assessment of safety and efficacy of drugs in pregnancy extremely difficult. Ivermectin has been classified as pregnancy category $\mathrm{C}$ by the FDA.

\section{Convalescent Plasma and Immune Globulins}

Plasma from convalescent patients and human immunoglobulin (IVIG) have been proposed by as alternatives containing the antibodies that could be able to reduce the viral load, decrease disease severity score and improve the oxygenation state of the transfused subjects. Available studies to support their use are limited to case reports and case series. according to a recent systemic review of five studies most of them conducted in china on small groups of patient exhibit improvement after plasma therapy in temperature and respiration [52]. Definitive conclusion can't be obtained due to high risk of bias, some weren't constant or performed on other RNA viruses [53-56] Although maximum dose of $2400 \mathrm{ml}$ is reported in 73 male patients in China [57], but optimal dose remained indefinite. Monoclonal antibodies are preferred due to their specificity, low risk of blood-borne pathogen infection [58]. FDA is permitting the emergency investigational use of convalescent plasma to treat COVID-19 under the criteria of the emergency IND.

\section{Antithrombotic Therapy}

There are two types of antithrombotic drugs anticoagulants and antiplatelet drugs. Anticoagulants slow down clotting, thereby reducing fibrin formation and preventing clots from forming and growing. Antiplatelet agents prevent platelets from clumping and also prevent clots from forming and growing [59]. In 1970, LMWH was produced chemically by splitting heparin into one-third of its original size. It has few side effects than heparin and has a more effect as an anticoagulant [59]. Aspirin is the first antiplatelet drug which used to relieve pain for more than 100 years. Then in 1960s, proven aspirin prevented platelets from clumping, and subsequent clinical trials showed that it reduces the risk of stroke and heart attack. In 1980, researchers showed that aspirin in very low doses (much lower than that required to relieve a headache) blocked the production of a chemical in platelets that is required for platelet clumping. During that time, better understanding of the process of platelet clumping allowed the development of designer antiplatelet drugs directed at specific targets $[59,60]$.

Once Aspirin reaches systemic circulation, it lacks antiplatelet activity. Aspirin achieve its maximum effect within 1 hour following an initial dose (325 mg), and to sustain its effect use very low dose $(40 \mathrm{mg} / \mathrm{d})$. Its dose ranges from $50 \mathrm{up}$ to $320 \mathrm{mg} / \mathrm{d}$ [61]. The most dosage prescribed is $(81 \mathrm{mg} / \mathrm{d})$ which called baby aspirin. Increasing dose of aspirin does not improve efficacy but increasing side effect especially gastrointestinal bleeding [62]. There are many roles of early use of aspirin in COVID-19 patients like inhibiting virus replication, anti-platelet aggregation, anti-inflammatory and anti-lung injury, is expected to reduce the incidence of severe and critical patients, shorten the length of hospital duration and reduce the incidence of cardiovascular complications.

Low-dose aspirin $(150 \mathrm{mg} / \mathrm{d})$ is effective in prevention of placental complications during pregnancy like pre-eclampsia and fetal growth restriction. Additionally, this low dose not associated with an increased risk of congenital defects, bleeding or premature closure of the ductus arteriosus [63]. 


\section{Antibacterial Therapy}

Antibacterial therapy should not be started by default, but only if we suspect bacterial infection; it is mandatory to monitor the patient's status with blood culture, urine analysis and urine culture and to start the appropriate therapy only in case of positive cases [64]. Based on the patient's clinical manifestation, if the bacterial infection cannot be excluded, it is possible to start a therapy for community-acquired pneumonia (amoxicillin, azithromycin) in mild cases of COVID-19 disease; in severe patients until specific bacteria are identified, all possible pathogens should be treated. For instance, intravenous ceftriaxone could be used while waiting for cultures, starting appropriate and specific antibiotic therapy, based on the specific infection, as soon as possible [64-66].

Amoxicillin belongs to the class of beta lactam antibiotics, is semi synthetic penicillin that produce a bactericidal action by inhibiting the synthesis of the bacterial cell wall. It has a wide spectrum of action against both gram positive and gram negative bacteria; it is used to treat most bacterial infections, in many cases amoxicillin is the first choice drug compared to other beta lactamic group of antibiotics, because it is much better absorbed through the oral route. Amoxicillin is classified as class B by FDA and commonly used in pregnancy and breastfeeding $[67,68]$.

Azithromycin belongs to a family of macrolide-type antibiotics and it works by inhibiting the protein biosynthesis and as a result the growth of bacteria (bacteriostatic drug). It has common side effects such as nausea, vomiting, diarrhea, abdominal pain and, less frequently some ECG changes as prolonging the QT interval. In fact, the addition of Azithromycin to the protocol with chloroquine it is not recommended as their combination may cause QT prolongation, with a greater risk of adverse cardiac effects.68 Azithromycin is classified as class B by FDA and commonly used in pregnancy and breastfeeding [69].

Ceftriaxone is a beta-lactam agent which considered as a member of third generation cephalosporins group and it has a bactericidal action by interfering with the synthesis of peptidoglycans (i.e. bacterial cell wall constituents). Compared to first and second generation cephalosporins, it has lower efficacy against Gram-positive bacteria but it has a higher activity against Gram-negative bacteria. It has common side effects like diarrhea, nausea or vomiting, pancreatitis, stomatitis, glossitis, and in general gastrointestinal symptoms. Ceftriaxone is classified as class B by FDA and commonly used in pregnancy and breastfeeding [70].

\section{Proton Pump Inhibitors (PPIs)}

Proton pump inhibitors (PPIs) remain central to management of acid-suppression disorders and are considered safe in the general population [71]. About two thirds of pregnant patients develop heartburn [72]. There are many factors which cause this, but the most significant one is a decrease in lower sphincter pressure of esophagus due to the female sex hormones, particularly progesterone. A prospective controlled cohort study was done on 295 pregnancies have deal with PPIs, 53 of them exposed to pantoprazole, and in comparison, with pregnancy outcomes with those of 868 control subjects. Rate of major congenital malformations in the group exposed to pantoprazole was $2.1 \%$ (1/48) compared with $3.8 \%$ in the control group (30/792) and no pattern of congenital anomalies [73]. PPIs have not a great teratogenic effect on pregnant women [74]. So pregnant women should choose an old PPI in a pharmacologic class that has the most fetal safety data that indicate the drug is effective. PPIs are classified as pregnancy category B.

\section{Angiotensin Converting Enzyme Inhibitors (ACE inhibitors) \& Angiotensin Receptor Blockers (ARBs)}

Studies showed that COVID-19 uses ACE2 receptors in a way similar to SARS CoV. Poor outcomes in patient with diabetes mellitus and hypertension support this theory due to over expression of these receptors. Recent studies showed that patients receiving ACE inhibitors are in danger of poor outcomes due to up regulation of these receptors [75]. For pregnant women, ACE inhibitors can lead to injury or even more death of the fetus $[76,77]$. That's why the FDA put them in category $\mathrm{C}$ in first trimester and category $\mathrm{D}$ in the second. Thus, in turn, their use in pregnancy is not recommended and if it is necessary, the cardiologist must be cautious [77-78].

\section{Host Directed Therapy (HDT)}

Host Directed Therapy (HDT) is considered a group of maneuvers working through modulating the host immunity to decrease the damage resulting from excessive inflammatory process [79]. Evidences from clinical practice show that patients with severe symptoms of COVID-19 disease may present with which is called cytokines storm. Cytokines storm presents with an excessive increase in levels of IL-2, IL-6, IL-10, granulocyte colony stimulating factor, TNF-alpha, which lead to organ damage4. HDT includes metformin, statins and glitazone.

Metformin improves the production of mitochondrial ROS and the macrophages autophagy [80], decreasing the damage of the lung in murine models by reducing the mitochondrial complex I [81]. Gilbert et al. studied the use of metformin in pregnancy particularly in the first 3 months which seemed to be safe as concerning congenital malformations [82]. Li et al., studied the metformin administration in women with gestational diabetes and showed a risk reduction of some complications like gestational hypertension, increase of glucose level and the need of intensive care admission for the neonate [83].

Statins works by inducing autophagy and phagocytic maturation and are used as anti-inflammatory agents in pulmonary infections [84]. There is a limited data on the effects of statins administration 
during pregnancy, but compared to the general population, they do not expect to result in major congenital malformations [85]. FDA assigned statins as category $\mathrm{X}$ in pregnancy, so it is contraindicated in pregnancy.

Glitazones target the cytokines overproduction. The main target is the peroxisome proliferator-activated receptor (PPAR)-c, which is considered a member of the PPAR transcription factor family, which causes inhibition of inflammatory process. PPAR-c synthetic agonists the family thiazolidinediones (TZDs), like pioglitazone, with known to have an ameliorating effect on severe viral pneumonia. Pioglitazone (30-45mg/day for 3 months) showed to significantly reduce IL-6 and TNF-alpha in people with insulin resistance [86]. The glitazones use in pregnancy has not been studied and most information come from case report of inadvertent use or therapeutic use for PCOS which resulted in normal outcome [87] or spontaneous abortion [88]. For the sake of that causes, pioglitazone has not been classified by FDA to be used in pregnancy.

\section{Ambroxol}

Ambroxol is secretolytic drug that has anti-inflammatory and anti-oxidant properties and can be used for cough and sore throat $[89,90]$. These symptoms are present in COVID-19 [91]. One of its great effects is reduction of pro-inflammatory cytokines 89. This effect is useful in cytokine storm and ARDS that happens in some of COVID-19 cases [24]. Despite all these advantages of Ambroxol, its use is not recommended in pregnancy and it is an FDA category C drug [92].

\section{Codeine}

Codeine is a narcotic used for pain relief, sedation and cough suppression [93]. It's an FDA class C pregnancy drug. Its use is not recommended during pregnancy. A small amount is metabolized into morphine in the body [93]. One of its dangers is neonatal narcotic withdrawal [94]. So, it can be used only of its use benefits overweight harms to the fetus [95]. It's better to be avoided in treatment of COVID-19 pregnant women but can be used if late cases in trial to save the mother

\section{Corticosteroids}

Antenatal Administration of corticosteroid is relatively common among pregnant women as it has immunosuppressive and anti-inflammatory effects. In early pregnancy, steroids are used to treat recurrent miscarriage or fetal problems. Furthermore, the antenatal administration of corticosteroids to mothers who at risk of preterm delivery is one of the most significant developments in perinatal medicine; corticosteroids which are administered antenatal now the most important part of care for pregnancies of anticipation of premature delivery in developed countries. This because of improvement of neonatal outcomes following antenatal corticosteroid administration. However, prednisone does not represent a fatal teratogenic risk in humans at therapeutic doses, it does increase the risk of oral cleft by an order of 3.4-fold, which is consistent with the existing animal studies [96].

Prematurity abnormalities showed a good decline in antenatal exposure to Corticosteroids, including perinatal death, neonatal death, moderate/severe RDS, intraventricular hemorrhage (IVH), necrotizing enterocolitis and systemic infections in the first 48 hours of life [97].

Some trials on children up to 12 years show that exposure to antenatal corticosteroids does not show any hinder or retard the somatic or psychomotor growth [98]. Antenatal corticosteroids are used for women at risk of premature birth and will decrease neonatal morbidity and mortality and save health care costs. A recent study, where a decision-analytic model was applied, showed that, in case of premature rupture of membranes in preterm, the administration of antenatal corticosteroids was an effective management plan when it was compared to no corticosteroid administration only at gestational ages less than 31 weeks [99]. There are some reports stated a potential worsening of the clinical conditions in already ill patient after betamethasone administration. As a result, a single dose of $12 \mathrm{mg}$ of betamethasone could be administered to minimize the effects on maternal blood glucose and on patient's clinical condition [100]. Therefore, the use of corticosteroids on the treatment of COVID-19 should be carefully evaluated because of the reduction of the host's inflammatory response in the lungs. FDA does not assign betamethasone in any category on the other hand, prednisolone and methylprednisolone are classified in category $\mathrm{C} / \mathrm{D}$ and $\mathrm{C}$ of FDA, respectively but corticosteroids generally are classified as US FAD category D [101].

\section{Non-Steroidal Anti-Inflammatory drugs (NSAIDs)}

NSAIDs are one of the most commonly used over-the counter (OTC) medications for the treatment of pain, inflammation and fever. It's action by inhibiting the activity of cyclooxygenase enzymes (COX-1 or COX-2) in cell. These enzymes produce prostaglandins (PGs), lipids which cause pain and fever101. There are two types of NSAIDs non-selective (ibuprofen) and COX-2 selective (celecoxib and diclofenac) [102]. Paracetamol (acetaminophen) is generally not considered an NSAID due to its minor anti-inflammatory effect. It relieves pain mainly by blocking COX-2 and inhibiting endocannabinoid reuptake almost exclusively within the brain [103].

Ibuprofen used as the second most OTC analgesic after paracetamol [104] and consider as the mildest NSAID due to its fewest side effects which has been in clinical use for a long time [105]. Long term use of NSAIDs associated with higher rates of side effect like myocardial infarction, heart failure, stroke and nephrotoxicity [106-108]. Acute respiratory tract infections are 
also associated with increased risk of stroke and myocardial infarction [106].

NSAIDs are associated with higher rates of complications after respiratory tract infections, including complicated pneumonia, pleural effusions, prolonged illness, peritonsillar abscess, dissemination of infection to more than one site, or suppuration. NSAIDs were also associated with delays in the prescription of effective antibiotic treatment for patients requiring hospital admission [107,108] so use of NSAID in patients who positive COVID-19 and has other comorbities may aggravate these symptoms [109]. However, NSAIDs are used in COVID-19 to relieve nighttime symptoms and aid sleep if paracetamol not enough as sleep is an important in immune defense. It also relieves musculoskeletal pain which annoying patients [110].

Ibuprofen is category $(\mathrm{B}, \mathrm{B}, \mathrm{D})$, paracetamol $(\mathrm{B}, \mathrm{B}, \mathrm{B})$ and aspirin (D,D,D) according FDA (U.S. Food and Drug Administration) Pregnancy risk classification by trimesters (1st,2nd,3rd).

The placental barrier is permeable to paracetamol and its metabolites. Its metabolites detect in the infant's urine after the mother had taken a few hours before delivery [111]. There are no conclusion association between paracetamol exposure in utero and cryptorchidism according to Data from epidemiological and animal studies about risks of malformations [112]. There is no direct measurement of the ability of ibuprofen to cross the placental barrier and its subsequent plasma levels in human fetuses. Ibuprofen and its metabolites enter the fetal circulation [113] and found in the meconium of newborn infants [114]

In the third trimester of pregnancy, all NSAIDs are contraindicated due to risks of severe cardiopulmonary toxicity and renal dysfunction in the fetus [115]. In the 1st trimester, non-selective COX inhibitors like ibuprofen decrease cell proliferation and increase cell death in human fetal ovaries mainly due to effects on fetal germ cells. 115

\section{Conclusion}

COVID-19 is a pandemic disease caused by the SARS-CoV-2 which spread globally in the last few months. Currently, there is no specific treatment for SARS-CoV-2. Additionally, many of effective drugs in general population cannot be used for pregnant women due to the lack of knowledge of side effects so clinicians should take into account benefits and possible adverse effects and initiate treatment when potential benefits outweigh potential risks and intra uterine development must be monitored closely during treatment and even after the treatment is stopped.

\section{Acknowledgment}

None.

\section{Conflict of Interest}

None.

\section{References}

1. Lu H, Stratton CW, Tang YW (2020) Outbreak of pneumonia of unknown etiology in Wuhan, China: The mystery and the miracle. J Med Virol 92(4): 401-402.

2. Heymann DL, Shindo N (2020) COVID-19: what is next for public health? Lancet 395(10224): 542-545.

3. Mor G, Aldo P, Alvero AB (2017) The unique immunological and microbial aspects of pregnancy. Nat Rev Immunol 17(8): 469-482.

4. Huang C, Wang Y, Li X, Ren L, Zhao J, et al. (2020) Clinical features of patients infected with 2019 novel coronavirus in Wuhan, China. Lancet 395(10223): 497-506.

5. Yockey LJ, Iwasaki A (2018) Interferons and Proinflammatory Cytokines in Pregnancy and Fetal Development. Immunity 49(3): 397-412.

6. Wong SF, Chow KM, Leung TN, Ng WF, Ng TK, et al. (2004) Pregnancy and perinatal outcomes of women with severe acute respiratory syndrome. Am J Obstet Gynecol 191(1): 292-297.

7. Liu H, Wang L-L, Zhao S-J, Kwak-Kim J, Mor G, et al. (2020) Why are pregnant women susceptible to COVID-19? An immunological viewpoint. J Reprod Immunol 139: 103122.

8. Schrezenmeier E, Dörner T (2020) Mechanisms of action of hydroxychloroquine and chloroquine: implications for rheumatology. Nat Rev Rheumatol 16(3): 155-166.

9. Addis A, Sharabi S, Bonati M (2000) Risk Classification Systems for Drug Use During Pregnancy. Drug Saf 23(3): 245-253.

10. Gao J, Tian Z, Yang X (2020) Breakthrough: Chloroquine phosphate has shown apparent efficacy in treatment of COVID-19 associated pneumonia in clinical studies. Biosci Trends 14(1): 72-73.

11. Carr RE, Henkind P, Rothfield N, Siegel IM (1968) Ocular Toxicity of Antimalarial Drugs. Am J Ophthalmol 66(4): 738-744.

12. Motta M, Tincani A, Faden D, Zinzini E, Lojacono A, et al. (2005) FollowUp of Infants Exposed to Hydroxychloroquine Given to Mothers during Pregnancy and Lactation. J Perinatol 25(2): 86-89.

13. Suhonen R (1983) Hydroxychloroquine administration in pregnancy. Arch Dermatol 119(3): 185-186.

14. Klumpp TG (1965) Safety of Chloroquine in Pregnancy. JAMA 191(9): 765.

15. Parke A (1988) Antimalarial drugs and pregnancy. Am J Med 85(4): 3033.

16. Mulangu S, Dodd LE, Davey RT, Tshiani Mbaya O, Proschan M, et al. (2019) A Randomized, Controlled Trial of Ebola Virus Disease Therapeutics. N Engl J Med 381(24): 2293-2303.

17. Singh AK, Singh A, Singh R, Misra A (2020) Remdesivir in COVID-19: A critical review of pharmacology, pre-clinical and clinical studies. Diabetes Metab Syndr Clin Res Rev 14(4): 641-648.

18. Pestka S, Krause CD, Walter MR (2002) Interferons, interferon-like cytokines, and their receptors. Immunol Rev 202(1): 8-32.

19. Guidelines T (2019) Coronavirus Disease 2019 (COVID-19) Treatment Guidelines. Disponible en.

20. Yazdani Brojeni P, Matok I, Garcia Bournissen F, Koren G (2012) A systematic review of the fetal safety of interferon alpha. Reprod Toxicol 33(3): 265-268.

21. Lu E, Wang BW, Guimond C, Synnes A, Sadovnick D, et al. (2012) Diseasemodifying drugs for multiple sclerosis in pregnancy: A systematic review. Neurology 79(11): 1130-1135. 
22. Hellwig K, Geissbuehler Y, Sabidó M, Popescu C, Adamo A, et al. (2020) Pregnancy outcomes in interferon-beta-exposed patients with multiple sclerosis: results from the European Interferon-beta Pregnancy Registry. J Neurol 267(6): 1715-1723.

23. Stebbing J, Phelan A, Griffin I, Tucker C, Oechsle O, et al. (2020) COVID-19: combining antiviral and anti-inflammatory treatments. Lancet Infect Dis 20(4): 400-402.

24. Huang C, Wang Y, Li X, Ren L, Zhao J, et al. (2020) Clinical features of patients infected with 2019 novel coronavirus in Wuhan, China. Lancet 395(10223): 497-506.

25. Olla D, Sawyer J, Sommer N, Moore JB (2020) Migraine Treatment. Clin Plast Surg 47(2): 295-303.

26. Monteagudo LA, Boothby A, Gertner E (2020) Continuous Intravenous Anakinra Infusion to Calm the Cytokine Storm in Macrophage Activation Syndrome. ACR Open Rheumatol 2(5): 276-282.

27. Flint J, Panchal S, Hurrell A, van de Venne M, Gayed M, et al. (2016) BSR and BHPR guideline on prescribing drugs in pregnancy and breastfeeding- Part II: analgesics and other drugs used in rheumatology practice. Rheumatology 55(9): 1698-1702.

28. Youngstein T, Hoffmann P, Gül A, Lane T, Williams R, et al. (2017) International multi-centre study of pregnancy outcomes with interleukin-1 inhibitors. Rheumatol 56(12): 2102-2018.

29. Liu B, Li M, Zhou Z, Guan X, Xiang Y (2020) Can we use interleukin-6 (IL6) blockade for coronavirus disease 2019 (COVID-19)-induced cytokine release syndrome (CRS)? J Autoimmun 111: 102452.

30. Xu X, Han M, Li T, Sun W, Wang D, et al. (2020) Effective treatment of severe COVID-19 patients with tocilizumab. Proc Natl Acad Sci 117(20): 10970-10975.

31. Favilli A, Mattei Gentili M, Raspa F, Giardina I, Parazzini F, et al. (2020) Effectiveness and safety of available treatments for COVID-19 during pregnancy: a critical review. J Matern Neonatal Med 7: 1-14.

32. Hoeltzenbein M, Beck E, Rajwanshi R, Gøtestam Skorpen C, Berber E, et al. (2016) Tocilizumab use in pregnancy: Analysis of a global safety database including data from clinical trials and post-marketing data. Semin Arthritis Rheum 46(2): 238-245.

33. Nakajima $K$, Watanabe $O$, Mochizuki $M$, Nakasone $A$, Ishizuka $N$, et al. (2016) Pregnancy outcomes after exposure to tocilizumab: A retrospective analysis of 61 patients in Japan. Mod Rheumatol 26(5): 667-671.

34. Flexner C (1998) HIV-Protease Inhibitors. N Engl J Med 338(18): 12811293.

35. Chan JF-W, Yao Y, Yeung M-L, Deng W, Bao L , et al. (2015) Treatment with Lopinavir/Ritonavir or Interferon- $\beta 1 \mathrm{~b}$ Improves Outcome of MERS-CoV Infection in a Nonhuman Primate Model of Common Marmoset. J Infect Dis 212(12): 1904-1913.

36. Cao B, Wang Y, Wen D, Liu W, Wang J, et al. (2020) A Trial of LopinavirRitonavir in Adults Hospitalized with Severe Covid-19. N Engl J Med 382(19): 1787-1799.

37. Liu W, Zhou P, Chen K, Ye Z, Liu F, et al. (2020) Efficacy and safety of antiviral treatment for COVID-19 from evidence in studies of SARSCoV-2 and other acute viral infections: a systematic review and meta-analysis. CMAJ 192(27): E734-E744

38. Stek AM, Mirochnick M, Capparelli E, Best BM, Hu C, et al. (2006) Reduced lopinavir exposure during pregnancy. AIDS 20(15): 1931-1939.

39. Sha BE, Tierney C, Sun X, Stek A, Cohn SE, et al. (2015) Pharmacokinetic Exposure and Virologic Response in Hiv-1 Infected Pregnant Women Treated with Lopinavir/Ritonavir: Aids Clinical Trials Group Protocol A5153s: A Sub study To A5150. Jacobs J AIDS/HIV 1(1): 003.

40. Patterson KB, Dumond JB, Prince HA, Jenkins AJ, Scarsi KK, et al. (2013) Protein binding of lopinavir and ritonavir during 4 phases of pregnancy: implications for treatment guidelines. J Acquir Immune Defic Syndr 63(1): 51-58
41. Else LJ, Douglas M, Dickinson L, Back DJ, Khoo SH, et al. (2012) Improved oral bioavailability of lopinavir in melt-extruded tablet formulation reduces impact of third trimester on lopinavir plasma concentrations. Antimicrob Agents Chemother 56(2): 816-824.

42. Salem AH, Jones AK, Santini-Oliveira M, Taylor GP, Patterson KB, et al. (2016) No Need for Lopinavir Dose Adjustment during Pregnancy: A Population Pharmacokinetic and Exposure-Response Analysis in Pregnant and Nonpregnant HIV-Infected Subjects. Antimicrob Agents Chemother 60(1): 400-408.

43. Cressey TR, Urien S, Capparelli EV, Best BM, Buranabanjasatean S, et al. (2015) Impact of body weight and missed doses on lopinavir concentrations with standard and increased lopinavir/ritonavir doses during late pregnancy. J Antimicrob Chemother 70(1): 217-224.

44. Bonafe SM, Costa DAG, Vaz MJR, Senise JF, Pott-Junior H, et al. (2013) A randomized controlled trial to assess safety, tolerability, and antepartum viral load with increased lopinavir/ritonavir dosage in pregnancy. AIDS Patient Care STDS 27(11): 589-595.

45. Boivin MJ, Maliwichi-Senganimalunje L, Ogwang LW, Kawalazira R, Sikorskii A, et al. (2019) Neurodevelopmental effects of ante-partum and post-partum antiretroviral exposure in HIV-exposed and uninfected children versus HIV-unexposed and uninfected children in Uganda and Malawi: a prospective cohort study. lancet HIV 6(8): E518-E530.

46. Highlights of Prescribing Information. These highlights do not include all the information needed to use PREZCOBIX ${ }^{\circledR}$ safely and effectively.

47. Stek A, Best BM, Wang J, Capparelli EV, Burchett SK, et al. (2015) Pharmacokinetics of Once Versus Twice Daily Darunavir in Pregnant HIV-Infected Women. J Acquir Immune Defic Syndr 70(1):33-41.

48. Preboth M (2000) The Antiretroviral Pregnancy Registry Interim Report. Am Fam Physician 61(7): 2265.

49. Pope R, Kashuba A (2017) Darunavir for use in pregnant women with HIV. Expert Rev Clin Pharmacol 10(12): 1317-1327.

50. Heidary F, Gharebaghi R (2020) Ivermectin: a systematic review from antiviral effects to COVID-19 complementary regimen. J Antibiot

51. Navarro M, Camprubí D, Requena-Méndez A, Buonfrate D, Giorli G, et al. (2020) Safety of high-dose ivermectin: a systematic review and metaanalysis. J Antimicrob Chemother 75(4): 827-834.

52. Nicolas P, Maia MF, Bassat Q, Kobylinski KC, Monteiro W, et al. (2020) Safety of oral ivermectin during pregnancy: a systematic review and meta-analysis. Lancet Glob Heal 8(1): E92-E100.

53. Rajendran K, Krishnasamy N, Rangarajan J, Rathinam J, Natarajan M, et al. (2020) Convalescent plasma transfusion for the treatment of COVID-19: Systematic review. J Med Virol.

54. Zhu T, Xu A, Bai X, He Y, Zhang H. Effect of convalescent plasma and immunoglobulin on patients with severe acute respiratory syndrome: a systematic review. Zhonghua Wei Zhong Bing Ji Jiu Yi Xue 32(4): 435438.

55. Zhang L, Liu Y (2020) Potential interventions for novel coronavirus in China: A systematic review. J Med Virol 92(5): 479-490.

56. Devasenapathy N, Ye Z, Loeb M, Fang F, Najafabadi BT, et al. (2020) Efficacy and safety of convalescent plasma for severe COVID-19 based on evidence in other severe respiratory viral infections: a systematic review and meta-analysis. Can Med Assoc J 192(27): E745-E755.

57. Zhang B, Liu S, Tan T, Huang W, Dong Y, et al. (2020) Treatment with Convalescent Plasma for Critically Ill Patients with Severe Acute Respiratory Syndrome Coronavirus 2 Infection. Chest 158(1): e9-e13.

58. Shanmugaraj B, Siriwattananon K, Wangkanont K, Phoolcharoen W (2020) Perspectives on monoclonal antibody therapy as potential therapeutic intervention for Coronavirus disease-19 (COVID-19). Asian Pacific J allergy Immunol 38(1): 10-18.

59. (2020) Antithrombotic Therapy - Hematology.org.

60. Bates SM, Rajasekhar A, Middeldorp S, McLintock C, Rodger MA, et al. (2018) American Society of Hematology 2018 guidelines for 
management of venous thromboembolism: Venous thromboembolism in the context of pregnancy. Blood Adv 2: 3317-3359.

61. Patrono C (1994) Aspirin as an antiplatelet drug. N Engl J Med 330(18): 1287-1294.

62. Blood Coagulation and Anticoagulant, Fibrinolytic, and Antiplatelet Drugs | Goodman \& Gilman's: The Pharmacological Basis of Therapeutics, 12e | AccessMedicine | McGraw-Hill Medical.

63. Rolnik DL, Wright D, Poon LCY, Syngelaki A, O'Gorman N, et al. (2017) ASPRE trial: performance of screening for preterm pre-eclampsia. Ultrasound Obstet Gynecol 50(4): 492-495.

64. Poon LC, Yang H, Kapur A, Melamed N, Dao B, et al. (2020) Global interim guidance on coronavirus disease 2019 (COVID-19) during pregnancy and puerperium from FIGO and allied partners: Information for healthcare professionals. Int J Gynecol Obstet 149(3): 273-286.

65. Jin Y-H, Cai L, Cheng Z-S, Cheng H, Deng T, et al. (2020) A rapid advice guideline for the diagnosis and treatment of 2019 novel coronavirus (2019-nCoV) infected pneumonia (standard version). Mil Med Res 7(1):

66. Liang H, Acharya G (2020) Novel corona virus disease (COVID-19) in pregnancy: What clinical recommendations to follow? Acta Obstet Gynecol Scand 99(4): 439-442.

67. (2000) Amoxicillin Drug Approval Package. Silver Spring (MD): FDA; Pharmacology review.

68. (2020) Waltham, Massachusetts, USA: Wolters Kluwer Health

69. (2006) Azithromycin Drug Approval Package Silver Spring (MD): FDA; Pharmacology review.

70. (2005) Ceftriaxone Drug Approval Package. Silver Spring (MD): FDA; Pharmacology review.

71. Raghunath AS, O'Morain C, McLoughlin RC (2005) Review article: the long-term use of proton-pump inhibitors. Aliment Pharmacol Ther 22 Suppl 1: 55-63.

72. Richter JE (2003) Gastroesophageal reflux disease during pregnancy. Gastroenterol Clin North Am 32(1): 235-261.

73. Diav-Citrin 0, Arnon J, Shechtman S, Schaefer C, Tonningen MR, et al. (2005) The safety of proton pump inhibitors in pregnancy: a multicentre prospective controlled study. Aliment Pharmacol Ther 21(3): 269-275.

74. Nikfar S, Abdollahi M, Moretti ME, Magee LA, Koren G (2002) Use of proton pump inhibitors during pregnancy and rates of major malformations: a meta-analysis. Dig Dis Sci 47(7): 1526-1529.

75. Rico-Mesa JS, White A, Anderson AS (2020) Outcomes in Patients with COVID-19 Infection Taking ACEI/ARB. Curr Cardiol Rep. 22(5): 31.

76.https://www.accessdata.fda.gov/drugsatfda_docs / label/2009/019777s056lbl.pdf

77. Ratnapalan S, Koren G (2002) Taking ACE inhibitors during pregnancy. Is it safe? Can Fam Physician 48(6).

78. http://www.ncbop.org/ PDF\%5CFDAAdvisoryACEIuseDuringPregnancyJune2006.pdf .

79. Zhao X, Jiang Y, Zhao Y, Xi H, Liu C, et al. (2020) Analysis of the susceptibility to COVID-19 in pregnancy and recommendations on potential drug screening. Eur J Clin Microbiol Infect Dis 39(7): 12091220 .

80. Beigel JH, Nam HH, Adams PL, Krafft A, Ince WL, et al. (2019) Advances in respiratory virus therapeutics - A meeting report from the $6^{\text {th }}$ isirv Antiviral Group conference. Antiviral Res 167: 45-67.

81. Zmijewski JW, Lorne E, Zhao X, Tsuruta Y, Sha Y, et al. (2008) Mitochondrial Respiratory Complex I Regulates Neutrophil Activation and Severity of Lung Injury. Am J Respir Crit Care Med 178(2): 168-179.
82. Gilbert C, Valois M, Koren G (2006) Pregnancy outcome after firsttrimester exposure to metformin: a meta-analysis. Fertil Steril. 86(3): 658-663.

83. Li G, Zhao S, Cui S, Li L, Xu Y, et al. (2015) Effect comparison of metformin with insulin treatment for gestational diabetes: a meta-analysis based on RCTs. Arch Gynecol Obstet 292(1): 111-120.

84. Fedson DS (2013) Treating influenza with statins and other immunomodulatory agents. Antiviral Res 99(3): 417-435.

85. Pollack PS, Shields KE, Burnett DM, Osborne MJ, Cunningham ML, et al. (2005) Pregnancy outcomes after maternal exposure to simvastatin and lovastatin. Birth Defects Res Part a Clin Mol Teratol 73(11): 888-896.

86. Xie X, Sinha S, Yi Z, Langlais PR, Madan M, et al. (2018) Role of adipocyte mitochondria in inflammation, lipemia and insulin sensitivity in humans: effects of pioglitazone treatment. Int J Obes 42(2): 213-220.

87. Yaris F, Yaris E, Kadioglu M, Ulku C, Kesim M, et al. (2004) Normal pregnancy outcome following inadvertent exposure to rosiglitazone, gliclazide, and atorvastatin in a diabetic and hypertensive woman. Reprod Toxicol 18(4): 619-621.

88. Ota H, Goto T, Yoshioka T, Ohyama N (2008) Successful pregnancies treated with pioglitazone in infertile patients with polycystic ovary syndrome. Fertil Steril 90(3): 709-713.

89. https://daignet.de/site-content/die daig/fachorgan/archiv/2008/ ejomr2008_vol13_12/Beeh.pdf.

90. Malerba M, Ragnoli B (2008) Ambroxol in the $21^{\text {st }}$ century: pharmacological and clinical update. Expert Opin Drug Metab Toxicol 4(8): 1119-1129.

91. Cascella M, Rajnik M, Cuomo A, Dulebohn SC, Di Napoli R (2020) Features, Evaluation and Treatment Coronavirus (COVID-19).

92. Al-Jedai AH, Balhareth SS, Algain RA (2012) Assessment of foetal risk associated with 93 non-US-FDA approved medications during pregnancy. Saudi Pharm J 20: 287-299.

93. (2020) Codeine for Pain Side Effects, Dosage, Addiction.

94.https: / / www.accessdata.fda.gov/drugsatfda_docs / label/2013/022402s006lbl.pdf.

95. Mangurten HH, Benawra R (1980) Neonatal Codeine Withdrawal in Infants of Nonaddicted Mothers. Pediatrics 65(1).

96. Park-Wyllie L, Mazzotta P, Pastuszak A, Moretti ME, Beique L, et al. (2000) Birth defects after maternal exposure to corticosteroids: prospective cohort study and meta-analysis of epidemiological studies. Teratology 62(6): 385-392.

97. Roberts D, Brown J, Medley N, Dalziel SR (2017) Antenatal corticosteroids for accelerating fetal lung maturation for women at risk of preterm birth. Cochrane Database Syst Rev 3(3): CD004454.

98. Effect of corticosteroids for fetal maturation on perinatal outcomes. NIH Consens Statement. 12(2):1-24.

99. Zhou CG, Packer CH, Hersh AR, Caughey AB (2020) Antenatal corticosteroids for pregnant women with COVID-19 infection and preterm prelabor rupture of membranes: a decision analysis. J Matern Neonatal Med: 1-9.

100. Kakoulidis I, Ilias I, Koukkou E (2020) SARS-CoV-2 infection and glucose homeostasis in pregnancy. What about antenatal corticosteroids? Diabetes Metab Syndr 14(4): 519-520.

101. (2020) Anti-inflammatories may aggravate Covid-19, France advises | World news | The Guardian.

102. Day RO, Graham GG (2004) The vascular effects of COX-2 selective inhibitors. Aust Prescr 27(6): 142-145.

103. Hinz B, Cheremina O, Brune K (2008) Acetaminophen (paracetamol) is a selective cyclooxygenase-2 inhibitor in man. FASEB J 22(2): 383-390. 
104. Thorpe PG, Gilboa SM, Hernandez-Diaz S, Lind J, Cragan JD, et al. (2013) Medications in the first trimester of pregnancy: most common exposures and critical gaps in understanding fetal risk. Pharmacoepidemiol Drug Saf 22(9): 1013-1018.

105. Rainsford KD (2009) Ibuprofen: pharmacology, efficacy and safety. Inflammopharmacology 17(6): 275-342.

106. Coxib and traditional NSAID Trialists' (CNT) Collaboration; Bhala N, Emberson J, Merhi A, Abramson S, Arber N, et al. (2013) Vascular and upper gastrointestinal effects of non-steroidal anti-inflammatory drugs: meta-analyses of individual participant data from randomised trials. Lancet 382(9894): 769-779.

107. Zhang X, Donnan PT, Bell S, Guthrie B (2017) Non-steroidal antiinflammatory drug induced acute kidney injury in the community dwelling general population and people with chronic kidney disease: systematic review and meta-analysis. BMC Nephrol 18(1): 256.

108. Wen Y-C, Hsiao F-Y, Chan KA, Lin Z-F, Shen L-J, et al. (2017) Acute Respiratory Infection and Use of Nonsteroidal Anti-Inflammatory Drugs on Risk of Acute Myocardial Infarction: A Nationwide Case-Crossover Study. J Infect Dis 215(4): 503-509.
109. Besedovsky L, Lange T, Haack M (2019) The Sleep-Immune Crosstalk in Health and Disease. Physiol Rev 99(3): 1325-1380.

110. Clavé S, Rousset-Rouvière C, Daniel L, Tsimaratos M (2019) The Invisible Threat of Non-steroidal Anti-inflammatory Drugs for Kidneys. Front Pediatr 7: 520 .

111. Levy G, Garrettson LK, Soda DM (1975) Letter: Evidence of placental transfer of acetaminophen. Pediatrics 55(6): 895.

112. (2012) Paracetamol during pregnancy: no particular danger for the child. Prescrire Int 21(129): 186-187.

113. Adams SS, Bough RG, Cliffe EE, Lessel B, Mills RFN (1969) Absorption, distribution and toxicity of ibuprofen. Toxicol Appl Pharmacol 15(2): 310-330.

114. Alano MA, Ngougmna E, Ostrea Jr EM, Konduri GG (2001) Analysis of Nonsteroidal Antiinflammatory Drugs in Meconium and Its Relation to Persistent Pulmonary Hypertension of the Newborn. Pediatrics 107(3): 519-523.

115. Black RA, Hill DA (2003) Over-the-Counter Medications in Pregnancy. Am Fam Physician 67(12): 2517-2524. 